Article

\title{
Study of Mesoscale Cloud System Oscillations Capable of Producing Convective Gravity Waves
}

\author{
Stavros Kolios ${ }^{1,2}$ \\ 1 Laboratory of Meteorology, Department of Physics, University of Ioannina, 45110 Ioannina, Greece; \\ stavroskolios@yahoo.gr \\ 2 Department of Geography, University of the Aegean, University Hill, 81100 Mytilene, Greece
}

Received: 27 January 2018; Accepted: 2 April 2018; Published: 4 April 2018

\begin{abstract}
Mesoscale Convective cloud Systems (MCSs) are frequent in the greater area of the Mediterranean basin throughout the year. During their lifecycle, they can oscillate and produce vertically propagated, atmospheric gravity waves. This study is an effort to detect MCSs with oscillating behavior around the Mediterranean, capable of producing convectively driven gravity waves (CGWs). Furthermore, typical MCS characteristics were calculated to identify the dynamics and the profile of the convective areas which can generate CGWs. Areal changes of the convective cloud tops in 15-min time-steps during the whole lifecycle of the MCSs were calculated to define the MCS oscillations. It was concluded that the MCSs that develop during nighttime as well as in the cold season of the year seem to contribute significantly to CGW production. Topography and specific sea areas like the Adriatic and the Ionian Sea play a catalytic role in triggering MCSs, which seem to contribute to CGW generation.
\end{abstract}

Keywords: mesoscale convective systems; convective gravity waves; Mediterranean basin

\section{Introduction}

Mesoscale Convective cloud Systems (MCSs) can oscillate during their lifecycle, generating convectively driven atmospheric gravity waves, e.g., [1,2]. Such oscillations and consequently, the convectively generated gravity waves that are produced, can impact atmospheric circulation mainly by their vertical propagation and the exchange of large amounts of momentum and energy between the upper troposphere and stratosphere [3-6]. At this point, it has to be noted that for the needs of the study, as oscillating behavior is characterized the areal (spatial) differences of their cloud tops (Figure 1). This behavior is considered often capable of producing convective gravity waves (hereinafter, CGWs). The CGWs that develop in the troposphere can modulate clouds and (re)generate convection. Therefore, they can affect precipitation processes as well as the amounts of water vapor in the troposphere $[5,7,8]$. Furthermore, there are studies which show that the vertical propagation of gravity waves launched by deep convection, up to the mesosphere, is linked with some sprite structures [9-14].

It is noteworthy to point out that the gravity waves can be triggered by many factors like topography, shear instability, and fronts, e.g., [6,15]. Nevertheless, one of the primary sources of tropospheric gravity wave generation, besides orography, is deep convection $[5,16,17]$.

In the recent study of [17], ten-year observations from an infrasound station were analyzed. In this study, it was concluded that thunderstorms are the major cause of gravity wave activity. In another recent study [16], balloon observations and model simulations were used to examine the role of the deep tropical convection in the generation of gravity waves.

Nevertheless, in the majority of the studies dealing with the gravity waves, there is a lack of the quantitative use of satellite imagery despite its satisfactory spatial and temporal resolution. In addition, 
there is a lack of studies which deal with the role of convection in CGW production, although multispectral satellite images are widely used in the detection and the monitoring of convective cloud systems which are considered an important source of gravity wave generation.

Considering that the oscillating behavior of the deep convective cloud systems during their lifecycle can produce CGWs, a large volume of multispectral Meteosat images was used in this study to detect cloud tops of Mesoscale Convective Systems (MCSs) and record their oscillations during their lifecycles. A set of parameters for the MCS and their oscillations are analyzed in an effort to reveal the mean profile of the MCSs which can produce CGWs. The domain of the study includes the greater area of the Mediterranean basin which is very active regarding the generation of mesoscale cloud convection [18-21].
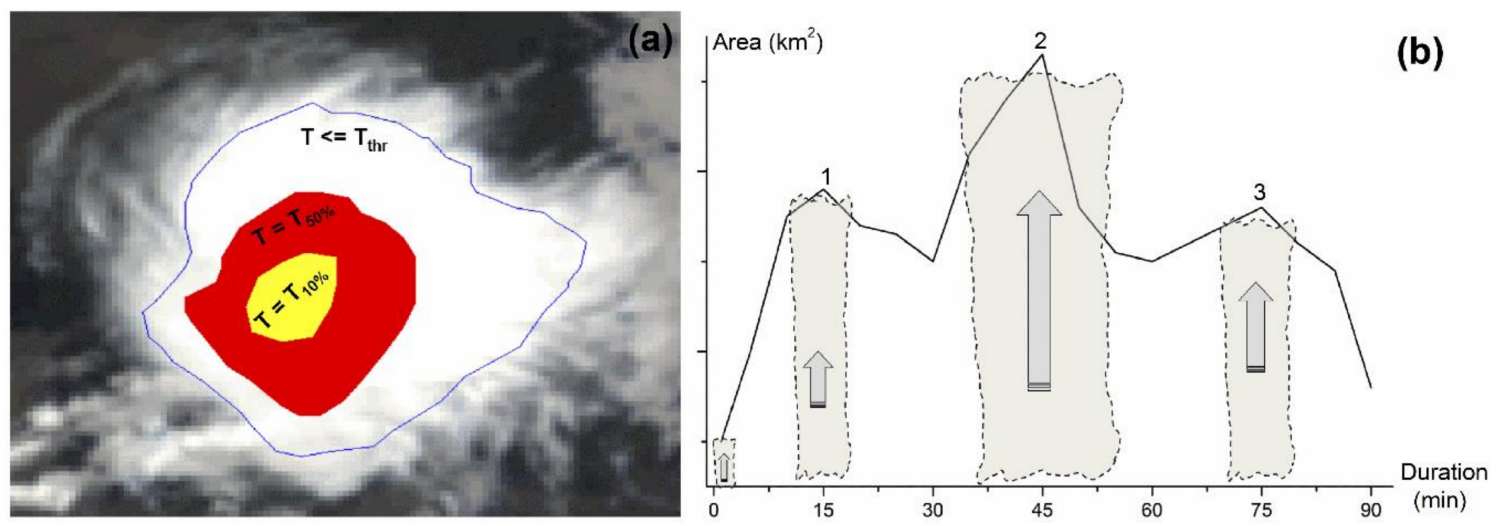

Figure 1. (a) A convective cloud cell as delimited through Meteosat imagery (Kolios, 2009). The red and yellow colored internal areas depict very cold isotherms where active convection can occur; (b) Schematic representation of the fluctuations regarding the cloud top areal extent during a typical MCS lifecycle. of the areal extent. Any of the local maxima that fulfill the criterion of the equation 1 was considered capable of producing CGWs.

\section{Materials and Methods}

A large volume of Meteosat-10 satellite images was used to collect a satisfactory dataset of mesoscale convective cloud tracks (hereinafter MCSs). More specifically, images from five bands (at the spectral centers of $6.2 \mu \mathrm{m} 7.3 \mu \mathrm{m}, 8.7 \mu \mathrm{m}, 10.8 \mu \mathrm{m}, 12.0 \mu \mathrm{m}$ ) in 15 min time-steps (typical operational temporal resolution of Meteosat imagery) during the period between 1 January 2016 and 31 December 2016 were collected. All these satellite images were analyzed through an automated algorithm that was developed to detect mesoscale convective patterns using multispectral Meteosat imagery and monitor their spatiotemporal evolution [22,23]. The efficiency and the overall accuracy of the applied algorithm are described analytically in the study [24]. The algorithm automatically creates lists with values of MCS parameters which characterize their spatiotemporal evolution and their internal dynamics. Among the calculated parameters are the minimum brightness temperature for all the used bands, the areal extent, the cloud speed and direction, the cloud percentages under specific thresholds, etc. $[19,22]$. In the current version of the algorithm, four different criteria are used in order to detect mesoscale convective cells (Table 1). At this point, it is mentioned that similar sets of criteria are widely used efficiently for the early detection of cloud convection using satellite imagery, e.g., [25]. Regarding the overlapping procedure of the algorithm which defines the continuity of the cloud cells in the different time-steps as parts of an MCS, the threshold value of $25 \%$ common areal extent was used. More specifically, if both of the compared cloud cells between two consecutive time-steps have a common area more than $25 \%$ in comparison with their total area, then these cloud-cells are considered two consecutive cloud cells of the MCS. 
Table 1. Criteria used to detect convective cloud cells (cloud tops) in the Meteosat images.

\begin{tabular}{cc}
\hline Detection Criteria & Threshold Values \\
\hline $\mathrm{BT}_{10.8 \mu \mathrm{m}}$ & $\leq 230 \mathrm{~K}$ \\
$\mathrm{BT}_{6.2 \mu \mathrm{m}}-\mathrm{BT}_{7.3 \mu \mathrm{m}}$ & $\geq-5 \mathrm{~K}$ \\
$\mathrm{BT}_{10.8 \mu \mathrm{m}}-\mathrm{BT}_{12.0 \mu \mathrm{m}}$ & $\leq 2.5 \mathrm{~K}$ \\
Area & $\geq 100 \mathrm{~km}^{2}$ \\
\hline
\end{tabular}

\section{MCS Oscillations}

During their lifecycle, the MCSs can oscillate mainly because of the fluctuations of updraft intensity which in turn can determine their vertical development, their cloud top areal extent and their lifetime. A schematic representation of this behavior is provided in Figure 1b. In the satellite imagery, the brightness temperature values are used to characterize the areal extent of the MCS cloud tops. Consequently, the brightness temperature variations can depict cloud top areal changes which are linked to the updraft characteristics and finally the oscillating behavior of these cloud systems which in turn can produce CGWs. More specifically, an abrupt increase of the cloud top extent of the MCS in a small period (15-min for the Meteosat-10 images) can characterize the size and the strength of the active convection but cause significant disturbances in the conditions of the higher troposphere. Nevertheless, the abrupt increase of the convective cloud top areas usually last short periods of time and the cloud areal decrease that follows finally leads to an overall abrupt spatial variation of the cold cloud tops capable of producing CGW. The satellite images of the SEVIRI (Spinning Enhanced Visible and Infrared Imager) instrument on board the Meteosat satellite platform can accurately detect the areal extent of the convective cloud tops because of its satisfactory spatial resolution (about $4 \mathrm{~km}$ in the domain of the study) and its high temporal resolution $(15 \mathrm{~min})$. Figure $1 \mathrm{~b}$ provides a schematic representation of the cloud top areal variations during the MCS lifecycle. Different maxima can be seen due to the forcing of the updrafts inside the vertical structure of the MCSs. The areal changes of the MCS cloud tops occur as the whole cloud system is moving in time and space. In this study, this motion was characterized as oscillating behavior.

In this study, all the local maxima of the cloud top areal extents during the MCS lifecycles were recorded. The most significant of them (the local maxima, which fulfills the criterion of Equation (1)) are considered to contribute to the production of CGWs (points " 1 ", " 2 " and " 3 " in Figure 1b). More analytically, the central scope of this study is to detect these areal maxima (considered capable of producing (GW) and relate them to typical MCS characteristics in order to identify the profile of the convective areas which can generate CGWs. For this reason, the criterion of Equation (1) was used to characterize the significance of the cloud areal variations which in turn can be linked with the CGW production. The criterion of Equation (1) means that the areal extent of a convective cloud top (Figure 1a) reaches a significant local maximum (hereinafter " $\mathrm{CC}_{\text {localmax }}$ ") when it is $3 \%$ larger than the cloud top areas of the previous and the next time-step.

$$
\frac{A_{t \pm 1}}{A_{t}} \leq 0.97
$$

where $A_{t}$ is the areal extent of the cloud top in the time-step " $t$ " while $A_{(t \pm 1)}$ is the cloud top areal extent for the previous (" $t-1$ ") and the next time-step (" $t+1$ ") in comparison with the time-step " $t$ ". At this point, it is noted that the criterion of the Equation (1) was chosen to discriminate abrupt and notable areal changes of the cloud tops from smaller ones. The abrupt and large areal changes can be linked with extensive atmospheric disturbances, significant enough to produce CGWs. In opposition, small areal changes of the cloud tops are usually connected mainly with the detection criteria in the satellite imagery and/or small fluctuations of the cloud top areal extent especially during the mature stage of the MCS life-cycles that cannot cause significant disturbances in the surrounding atmospheric environment. 


\section{Results and Discussion}

The results of the study concern only convective clouds with at least one significant areal oscillation (as was defined by Equation (1)). There were 2344 MCSs which fulfill the criterion of Equation (1) of 3507 MCSs in total during the examined period. The analysis is twofold. More specifically, the analysis is focused firstly on the basic characteristics of every convective cloud cell in the time of a significant local spatial maximum (" $\mathrm{CC}_{\text {localmax" }}$ event) and secondly on the mean profile of the convective clouds (MCSs) with at least one $\mathrm{CC}_{\text {localmax }}$ during their lifecycle. Additionally, the dataset of the MCS with $\mathrm{CC}_{\text {localmax }}$ events was split into different sub-categories in an effort to find out possible significant differences regarding their preferable time of occurrence in daily and seasonal basis as well as their geographic location. At this point, it must be noted that the analysis of the $\mathrm{CC}_{\text {localmax }}$ events is performed because it is considered to represent the capability of CGW production.

\subsection{Analysis of CGW Events}

As mentioned above, for each convective cloud cell which was labeled as $\mathrm{CC}_{\text {localmax }}$, some basic parameters were calculated. A total number of $5344 \mathrm{CC}_{\text {localmax }}$ cases was found. For this number of cases, their mean, standard deviation, median and as well as the $Q_{25}$ and $Q_{75 \%}$ quartiles were finally computed (Table 2).

Table 2. Basic descriptive statistics for the distribution (total number of 5344 events) of the convective clouds cells which represent $\mathrm{CC}_{\text {localmax }}$ cases.

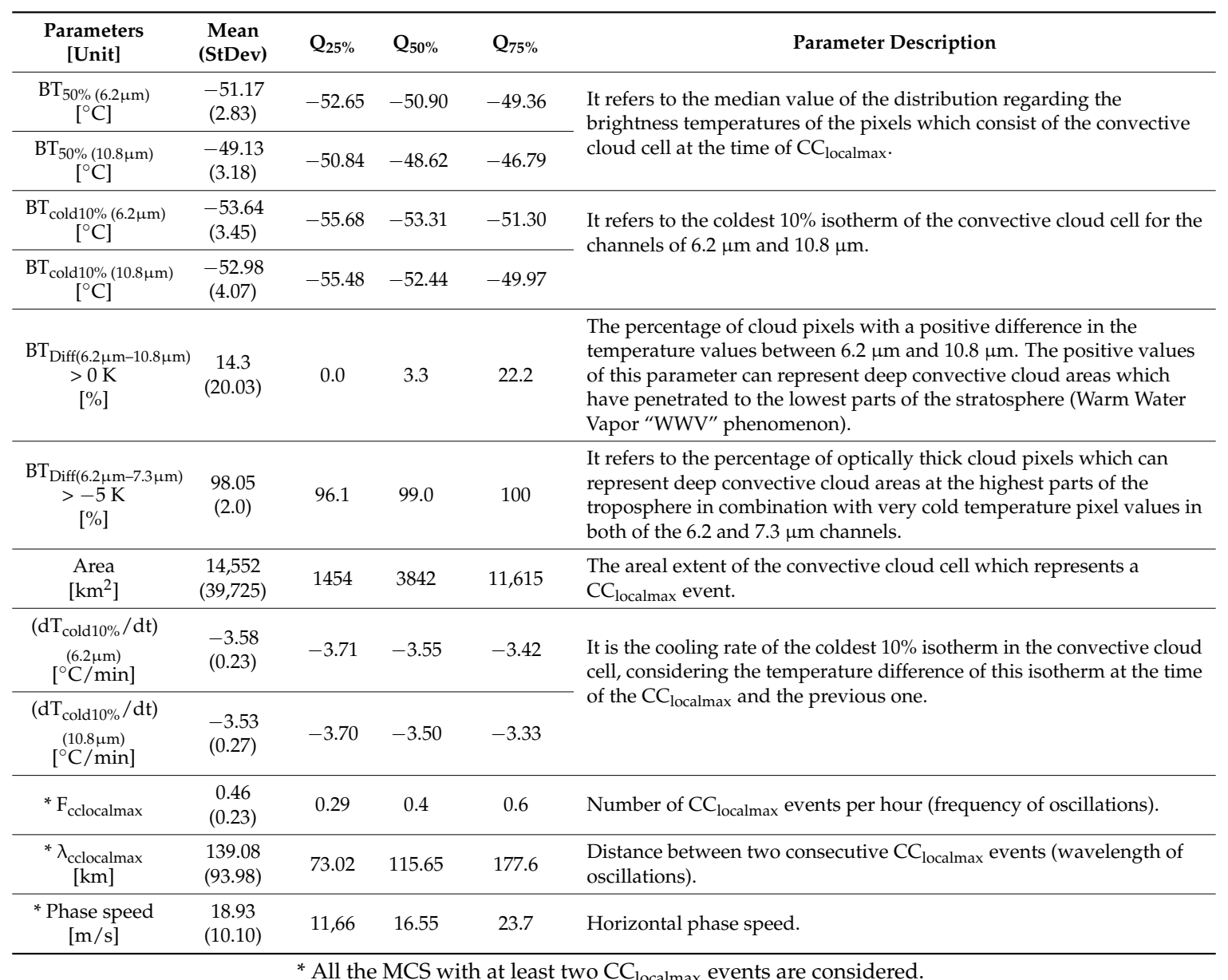


As can be seen from Table 2, the convective cloud cells, which correspond to $\mathrm{CC}_{\text {localmax }}$ cases, belong to very cold cloud tops with median temperatures reaching $-50{ }^{\circ} \mathrm{C}$ with their coldest areas

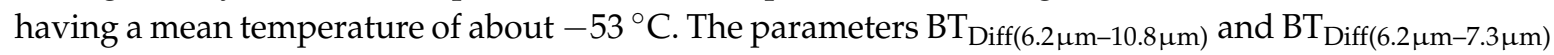
are indicative of cloud cell thickness, representing deep and active convective cloud areas that reach the highest parts of the troposphere, e.g., $[7,26]$. The mean values of these two parameters are above $98 \%$. Even their lowest values, which are represented by the statistic $Q_{25} \%$, are above $97 \%$. Such high values of these parameters highlight that practically, the whole convective cells at the time of $\mathrm{CC}_{\text {localmax }}$ are thick clouds, with an areal extent of thousand square kilometers and very cold cloud tops, reaching the upper limits of the troposphere. Moreover, about $14 \%$ (mean value of the $\mathrm{BT}_{\text {Diff }(6.2 \mu \mathrm{m}-10.8 \mu \mathrm{m})}$ in Table 2) of their total areal extent can be considered to belong to overshooting tops of cloud anvils. These cloud areas are possible to have penetrated the lowest parts of the stratosphere $[27,28]$ where the temperature inversion can lead to positive values of the $\mathrm{BT}_{\text {Diff( }(6.2 \mu \mathrm{m}-10.8 \mu \mathrm{m})}$ parameter. Additionally, the mean cooling rates of the coldest $10 \%$ isotherm in the convective cloud cell are slightly above $-3.5^{\circ} \mathrm{C} / \mathrm{min}$ in both the $6.2 \mu \mathrm{m}$ and $10.8 \mu \mathrm{m}$ channels. Such cooling rates can be considered significant enough and highlight the existence of strong updrafts inside the convective cells. The mean number of $\mathrm{CC}_{\text {localmax }}$ events per hour (frequency of oscillations) is 0.46 or one event every $133 \mathrm{~min}$, on average. The mean distance between two consecutive $\mathrm{CC}_{\text {localmax }}$ events (wavelength of oscillations) is $139.08 \mathrm{~km}$ while the mean horizontal speed was $18.9 \mathrm{~m} / \mathrm{s}$, i.e., statistics that are similar to other related studies [17].

Consequently, it can be noted that all the values of the parameters $n$ Table 2 show that the cloud areas that represent $\mathrm{CC}_{\text {localmax }}$ events are cloud areas with well-organized convection reaching high in the troposphere, with significant cooling rates that represent updrafts which can lead to overshooting tops. Additionally, on average, every $133 \mathrm{~min}$ and $139.08 \mathrm{~km}$, such abrupt areal changes of the MCS cloud tops $\left(\mathrm{CC}_{\text {localmax }}\right.$ events), can be recorded, creating in this way favorable initial conditions for CGW production.

\subsection{MCS-CQW Correlation}

In the effort to detect MCS characteristics that are notably linked with the CGWs, basic MCS parameters were correlated with the total number of $\mathrm{CC}_{\text {localmax }}$ events during the MCS lifecycle (the $\mathrm{CC}_{\text {localmax }}$ events are considered to represent the capability of CGW production). The results of these correlations are provided in Table 3. The Spearman Correlation coefficient [29] was used because of the non-normal distribution of the parameter values. In Table 3, only the statistically significant correlations are shown ( $95 \%$ statistical confidence level).

Table 3. Spearman Correlation coefficients among the number of $\mathrm{CC}_{\text {localmax }}$ events and MCS parameters. All the correlation coefficients are statistically significant at the 0.05 level.

\begin{tabular}{ccc}
\hline A/A & $\begin{array}{c}\text { MCS Parameter Values- } \\
\text { Number of } \mathrm{CC}_{\text {localmax }} \text { Events }\end{array}$ & Corr. Coeff. \\
\hline 1 & Duration- $\mathrm{CC}_{\text {localmax }}$ & 0.57 \\
2 & Total Distance-CC $C_{\text {localmax }}$ & 0.45 \\
3 & Max. Area-CC $C_{\text {localmax }}$ & 0.28 \\
4 & {$\left[\mathrm{BT}_{\text {cold } 10 \%(10.8 \mu \mathrm{m})}\right]_{\min }-\mathrm{CC}_{\text {localmax }}$} & -0.15 \\
5 & {$\left[\mathrm{BT}_{\text {cold } 10 \%(6.2 \mu \mathrm{m})}\right]_{\min }-\mathrm{CC}_{\text {localmax }}$} & -0.14 \\
\hline
\end{tabular}

In Table 3, it can be seen that five parameters which characterize the size of the MCS cloud tops, the internal dynamics and their duration in time and space are statistically significantly related to the production of CGWs. The long-lasting MCSs can produce more $\mathrm{CC}_{\text {localmax }}$ events and in turn, possibly a large number of CGWs. Also, the non-stationary MCSs usually cover large total distances, resulting in large numbers of CGW events. This finding may be linked to the vertical wind shear and the overall internal dynamics of the non-stationary convective cloud systems which may enhance the oscillating behavior of the MCS. The internal dynamics and more specifically, the varying intensity of 
the updrafts, can significantly affect the areal extent of the cloud tops, especially at the mature stage of the MCSs. The more intense and persistent the updrafts, the more extended are the cloud tops and the higher in the troposphere they can reach, which means lower brightness temperatures. The negative correlation between minimum brightness temperatures and $\mathrm{CC}_{\text {localmax }}$ events means that very cold cloud tops are more capable of producing CGW.

Figure $2 \mathrm{a}, \mathrm{b}$ presents the number of $\mathrm{CC}_{\text {localmax }}$ events and the MCSs on a monthly and daily basis, respectively. The ratio of these two numbers was also calculated in order to depict the preferable period of the day or the period of the year where the MCSs usually have large numbers of $\mathrm{CC}_{\text {localmax }}$ events.

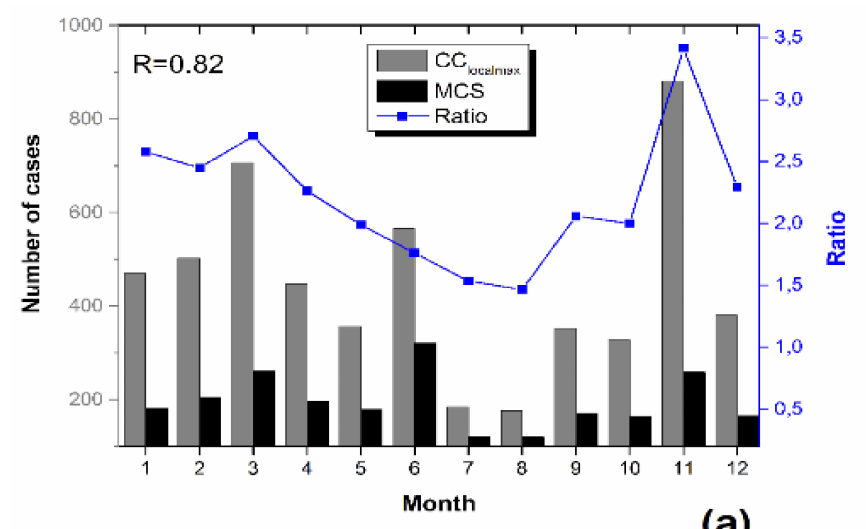

(a)

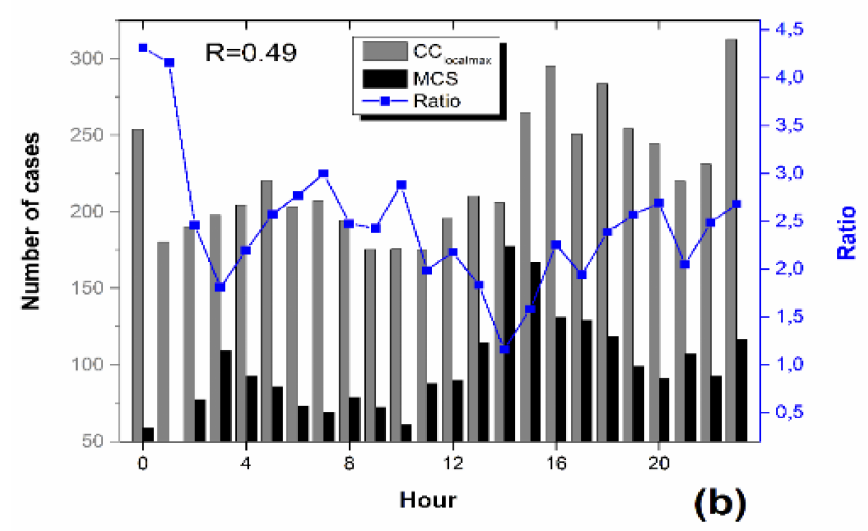

Figure 2. (a) Monthly number of $\mathrm{CC}_{\text {localmax }}$ events (gray bars) and MCSs (blackn bars). Their ratio is also presented (blue line); (b) The daily number of $\mathrm{CC}_{\text {localmax }}$ events (gray bars) and MCSs (green bars). Their ratio is also presented (blue line). The correlation coefficients are statistically significant at the 0.05 level.

From Figure 2a, it can be seen that during the warm period, the smallest numbers in both of the MCS and the $\mathrm{CC}_{\text {localmax }}$ events are recorded. In opposition, large numbers of MCS and $\mathrm{CC}_{\text {localmax }}$ events are recorded during the whole cold period of the year. During the autumn and the winter, the ratio of $\mathrm{CC}_{\text {localmax }}$ events according to the number of MCSs has its highest values. This mean ratio is 2.44 for the winter months and 2.49 for the autumn. The spring has a mean ratio of 2.32 and the smallest mean value (1.6) occurs in the summer. These results highlight that during the autumn and the winter, a significant number of MCSs can develop in the whole Mediterranean region that are capable of producing CGW. More specifically, the thermal convection which predominates especially during summer seems incapable of causing an oscillating behavior of the MCSs and consequently, significant atmospheric disturbances in the higher levels of the troposphere. Nevertheless, during the autumn and the winter, the convective activity (which seems to be capable of producing multiple $\mathrm{CC}_{\text {localmax }}$ events) is possibly linked with the relatively warm sea surface temperature profile of large parts across the Mediterranean Sea. Indeed, the warmer sea than the air above it, especially during 
winter, can cause a transfer of thermal energy and water vapor in the lower part of the troposphere, increasing the instability and thus the probability of triggering convection. Also, as expected, there is a strong positive correlation (Correlation Coefficient: 0.82 ) between the monthly number of MCSs and the $\mathrm{CC}_{\text {localmax }}$ events. This result highlights the increase of CGW with the increase of the MCS frequency of occurrence in the area of interest.

In Figure $2 b$, the daily variations in the numbers of $\mathrm{CC}_{\text {localmax }}$ events and the MCSs are presented. Considering the daytime from the ninth hour to the twentieth LST (Local Solar Time), the mean ratio (number of $\mathrm{CC}_{\text {localmax }}$ events/number of MCS) is 2.16, while at nighttime (LST) the mean ratio reaches 2.75. However, at this point, it must be noted that there is a small time-lag between the time of the MCS initiation and the time of the existence of a $\mathrm{CC}_{\text {localmax }}$ event. This time-lag can slightly shift the number of $\mathrm{CC}_{\text {localmax }}$ events one (or a few) hour(s) later, but the mean duration of the examined MCS with at least one $\mathrm{CC}_{\text {localmax }}$ event is about $5 \mathrm{~h}$ (Table 4). This means that although a time-lag can exist, a notable number of these events occur during nighttime. A possible cause for these daily distributions is that at noon and in the early afternoon, the atmosphere is typically characterized by increased instability and the thermal causes predominate in the triggering of cloud convection. As a result, during this period of the day, usually the largest number of the MCSs is recorded, and a few hours later, a large number of $\mathrm{CC}_{\text {localmax }}$ events can exist (Figure $2 b$ ). The largest number of $\mathrm{CC}_{\text {localmax }}$ events ( 312 cases) was found around midnight (Figure $2 b$ ). Also, the largest values of the ratio between the number of $\mathrm{CC}_{\text {localmax }}$ events and the number of MCSs are recorded during the nighttime, especially around midnight (Figure 2b). This result highlights that thermal causes and the enhanced instability in the atmosphere mainly during the daytime can be sufficient factors to create strong updrafts which lead to extended and well-organized cloud convective systems, especially during the late afternoon which in turn, can lead to $\mathrm{CC}_{\text {localmax }}$ events a few hours later.

Table 4. Basic descriptive statistics for the number of MCSs with at least one $\mathrm{CC}_{\text {localmax }}$ event during their lifecycle. The values of the parameter "BT $\mathrm{Diff}_{(6.2 \mu \mathrm{m}-10.8 \mu \mathrm{m})}$ " refer only to the number of the MCSs where at least one cloud cell during their lifecycles fulfill this criterion "BT $\operatorname{Diff}_{(6.2 \mu \mathrm{m}-10.8 \mu \mathrm{m})}>0 \mathrm{~K}^{\prime}$ (596 MCS out of 2344 in total).

\begin{tabular}{|c|c|c|c|c|c|}
\hline MCS Parameters [Units] & Mean & StDev & $\begin{array}{c}\text { 1st Quartile } \\
\left(Q_{25 \%}\right)\end{array}$ & $\begin{array}{c}\text { Median } \\
\left(Q_{50 \%}\right)\end{array}$ & $\begin{array}{c}\text { 3rd Quartile } \\
\left(Q_{75 \%}\right)\end{array}$ \\
\hline Duration [min] & 311.3 & 191.2 & 180.0 & 255.0 & 375.0 \\
\hline Total Distance [km] & 353.4 & 331.3 & 150.2 & 245.9 & 429.0 \\
\hline$(\text { Areal Extent })_{\max }\left[\mathrm{Km}^{2}\right]$ & $13,869.5$ & $25,402.8$ & 3565.2 & 6812.3 & $14,993.8$ \\
\hline Cloud Speed $[\mathrm{Km} / \mathrm{h}]$ & 42.6 & 11.7 & 30.9 & 38.4 & 50.8 \\
\hline $\begin{array}{c}\text { Total number of local maxima } \\
\text { [unitless] }\end{array}$ & 2.3 & 1.7 & 1.0 & 2.0 & 3.0 \\
\hline Channel $10.8 \mu \mathrm{m}$ : $\left(\mathrm{BT}_{\text {cold } 10 \%}\right)_{\min }[\mathrm{K}]$ & -55.2 & 3.9 & -57.7 & -54.8 & -52.2 \\
\hline Channel $6.2 \mu \mathrm{m}$ : $\left(\mathrm{BT}_{\text {cold } 10 \%}\right)_{\min }[\mathrm{K}]$ & -54.9 & 3.4 & -57.1 & -54.7 & -52.5 \\
\hline $\mathrm{BT}_{\operatorname{Diff}(6.2 \mu \mathrm{m}-10.8 \mu \mathrm{m})}>0 \mathrm{~K}[\%]$ & 14.87 & 0.16 & 2.25 & 8.03 & 22.9 \\
\hline $\mathrm{BT}_{\operatorname{Diff}(6.2 \mu \mathrm{m}-7.3 \mu \mathrm{m})}>-5 \mathrm{~K}[\%]$ & 98.2 & 1.9 & 97.5 & 98.8 & 99.6 \\
\hline
\end{tabular}

During the night and early morning, when a cold and dense air mass interacts with a warm one (a phenomenon which is common along coastlines of the Mediterranean basin due to the land-sea temperature distribution), a convergence zone forms that may enhance vertical movements of the warm and moist sea air [30,31]. This convergence can trigger the development of MCSs and moreover, these MCS seem to be capable of producing CGWs. The correlation coefficient between the daily number of MCSs and the number $\mathrm{CC}_{\text {localmax }}$ events is 0.49 which is a notable but not a strong correlation. This finding means that, on a daily basis, the atmospheric factors which can trigger convection capable of CGW production are not as significant as on a monthly basis, for which the relative correlation coefficient is 0.82 . 


\subsection{MCS Basic Characteristics}

As mentioned above, the mean profile of the MCSs with at least one $\mathrm{CC}_{\text {localmax }}$ event during their lifecycle (2344 MCS in total) was also examined by calculating basic descriptive statistics during their whole lifecycle (Table 4). It was concluded that the mean duration of these MCSs is $311 \mathrm{~min}(5.18 \mathrm{~h})$ and their mean distance traveled exceeded $300 \mathrm{~km}$. These MCSs are moving with a mean speed of 42.6 $\mathrm{Km} / \mathrm{h}$ while their mean area at the time where they reach their maximum horizontal areal extent is $13,869 \mathrm{Km}^{2}$. Additionally, more than three $\mathrm{CC}_{\text {localmax }}$ events occur in $25 \%$ of these MCSs (586 MCSs of the total number of 2344 cloud systems) while the mean number of their occurrence is two $\mathrm{CC}_{\text {localmax }}$ events. The minimum brightness temperature of MCS cloud tops regarding two basic channels (6.2 and $10.8 \mu \mathrm{m}$ ) an average value of $-55^{\circ} \mathrm{C}$ (Table 4$)$.

In summary, the MCSs with $\mathrm{CC}_{\text {localmax }}$ events during their lifecycles are well-organized in the mesoscale according to their mean areal extent, as well as relatively long-lasting and non-stationary because of their mean duration and the mean speed values (Table 4). It is also noted that these cloud systems are optically thick, almost in all their areal extent (the statistical values of the threshold “BT ${ }_{\text {Diff( } 6.2 \mu \mathrm{m}-7.3 \mu \mathrm{m})}>-5$ " are above $97 \%$ of the MCS areal extent) as it is defined by the criteria set according to the Table 1. Furthermore, it was found that the warm water vapor phenomenon $\left(\mathrm{BT}_{\text {Diff }(6.2 \mu \mathrm{m}-10.8 \mu \mathrm{m})}>0\right)$ was present in $25.4 \%$ of the total number of MCSs with at least one $\mathrm{CC}_{\text {localmax }}$ event. According to Table 4, in these MCSs, $15 \%$ of their mean areal extents have a positive temperature difference in the channels $6.2 \mu \mathrm{m}$ and $7.3 \mu \mathrm{m}$. Also, $75 \%\left(\mathrm{Q}_{75 \%}\right)$ of the MCSs total number, reach to areal extent of their cloud tops with positive values of the temperature difference $\mathrm{BT}_{\text {Diff( }(6.2 \mu \mathrm{m}-10.8 \mu \mathrm{m}) \text {, }}$ larger than $20 \%$.. These results mean that a notable number of MCSs and significant parts of their cloud tops are characterized by overshooting tops or areas where the intensity of the updrafts can lead large parts of these cloud systems to the upper limit of the troposphere (tropopause) and probably the lowest parts of the stratosphere. The strength of these updrafts is capable of producing $\mathrm{CC}_{\text {localmax }}$ events that indicate the existence of CGWs in high atmospheric altitudes.

\subsection{Daily Characteristics}

The dataset with the MCSs with at least one $\mathrm{CC}_{\text {localmax }}$ was split between daytime and nighttime MCSs according to their first time of detection. All the cloud systems, having their first detection between 09:00 and 20:59 Local Solar Time (LST), were categorized as daytime MCSs, while the rest of them were categorized as nighttime. According to Table 5, in the majority of the basic parameters which characterize daytime and nighttime MCSs, their mean values are very close. Nevertheless, statistically significant differences ( $95 \%$ statistical confidence level) were found in five out of nine examined parameters. The MCSs initiated during the nighttime cover larger total distance with higher mean speed in opposition to the daytime ones. The mean number of $\mathrm{CC}_{\text {localmax }}$ events of the nighttime MCSs was larger than the relative number of daytime MCSs and were statistically significant. Additionally, the minimum value for the colder 10\% isotherms (Figure 1a) during the MCS lifecycles was calculated in both of the 6.2 and $10.8 \mu \mathrm{m}$ channels. It was found that the daytime MCSs have colder isotherms than those of the nighttime. The values (percentages) of the parameters which concern the most convective areas and the overshooting tops $\left(\mathrm{BT}_{(\mathrm{Diff} 6.2 \mu \mathrm{m}-10.8 \mu \mathrm{m})}\right.$ and $\left.\mathrm{BT}_{(\mathrm{Diff} 6.2 \mu \mathrm{m}-7.3 \mu \mathrm{m})}\right)$ are similar (Table 5).

Moreover, maps regarding the spatial density of the MCS initiation location (location of the first detection) were created for both the daytime and the nighttime samples (Figure 3). The daytime MCSs (Figure 3a) are concentrated mainly around the significant mountainous regions of the study area and specifically around the Alps, the Carpathian mountain ridge, the Dinaric Alps and along the eastern part of the Apennines (the Italian Peninsula). Notable concentrations are also depicted in the Pyrenees Mountains (Iberian Peninsula) and the northern part of the Pindos mountain ridge (Greece). 
Table 5. Basic descriptive statistics for the number of MCSs with at least one $\mathrm{CC}_{\text {localmax }}$ event during daytime and nighttime. The values of the parameter "BT $\mathrm{Diff}_{(6.2 \mu \mathrm{m}-10.8 \mu \mathrm{m})}$ " refer only to the number of MCSs where at least one cloud cell during an MCS lifecycle fulfills this criterion "BT ${ }_{\text {Diff }(6.2 \mu \mathrm{m}-10.8 \mu \mathrm{m})}>$ $0 \mathrm{~K}^{\prime \prime}$ (596 MCS out of 2344 in total). The asterisk ("**) represents statistically significant differences between the mean values ( $95 \%$ statistical confidence level).

\begin{tabular}{|c|c|c|c|c|c|c|c|}
\hline $\begin{array}{l}\text { MCS Parameters } \\
\text { [Units] }\end{array}$ & $\begin{array}{c}\text { Period of Day } \\
\text { Day: “0" } \\
\text { Night: "1" }\end{array}$ & $\mathbf{N}$ & Mean & StDev & $\begin{array}{c}\text { 1st } \\
\text { Quartile } \\
\left(Q_{25 \%}\right)\end{array}$ & $\begin{array}{c}\text { Median } \\
\left(Q_{50 \%}\right)\end{array}$ & $\begin{array}{c}\text { 3rd } \\
\text { Quartile } \\
\left(Q_{75 \%}\right)\end{array}$ \\
\hline \multirow{2}{*}{$\begin{array}{l}\text { Duration } \\
\text { [min] }\end{array}$} & 0 & 1297 & 311.4 & 191.8 & 180.00 & 255.00 & 375.00 \\
\hline & 1 & 1047 & 311.2 & 190.5 & 180.00 & 255.00 & 375.00 \\
\hline \multirow{2}{*}{$\begin{array}{c}\text { * Total Distance } \\
{[\mathrm{km}]}\end{array}$} & 0 & 1297 & 338.8 & 328.1 & 141.84 & 235.17 & 436.07 \\
\hline & 1 & 1047 & 358.9 & 335.3 & 163.03 & 256.12 & 422.09 \\
\hline \multirow{2}{*}{$\begin{array}{c}* \text { Cloud Speed } \\
{[\mathrm{Km} / \mathrm{h}]}\end{array}$} & 0 & 1297 & 41.8 & 11.7 & 33.09 & 41.59 & 49.53 \\
\hline & 1 & 1047 & 43.7 & 11.7 & 35.16 & 43.66 & 51.86 \\
\hline \multirow{2}{*}{ * Total number of local maxima [unitless] } & 0 & 1297 & 2.1 & 1.7 & 1.00 & 2.00 & 3.00 \\
\hline & 1 & 1047 & 2.4 & 1.6 & 1.00 & 2.00 & 3.00 \\
\hline \multirow{2}{*}{$\begin{array}{c}\mathrm{BT}_{\operatorname{Diff}(6.2 \mu \mathrm{m}-10.8 \mu \mathrm{m})}>0 \mathrm{~K} \\
{[\%]}\end{array}$} & 0 & 334 & 16.3 & 15.1 & 2.7 & 9.9 & 25.7 \\
\hline & 1 & 262 & 13.1 & 11.2 & 1.7 & 6.8 & 20.2 \\
\hline \multirow{2}{*}{ 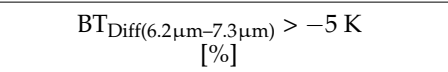 } & 0 & 1297 & 98.26 & 1.9 & 97.6 & 98.6 & 99.5 \\
\hline & 1 & 1047 & 98.19 & 1.9 & 97.4 & 98.8 & 99.6 \\
\hline
\end{tabular}

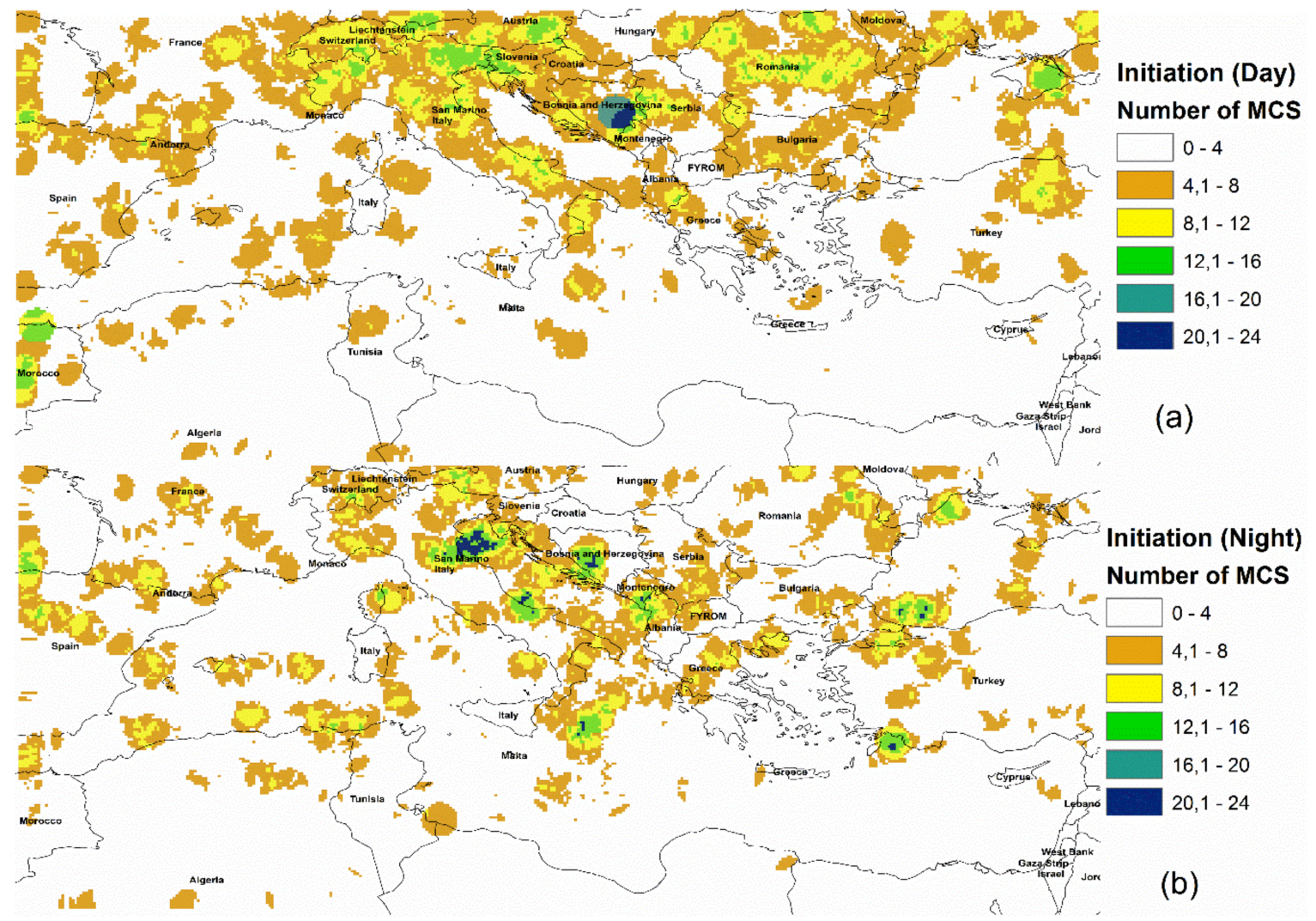

Figure 3. Spatial density of occurrence of MCSs with at least one $\mathrm{CC}_{\text {localmax }}$ event during (a) daytime; (b) nighttime. 
Regarding the nighttime MCSs capable of producing CGWs (Figure 3b), the density of their initiation location is more widespread than those of daytime. Also, high concentrations are located in sea areas and more specifically in the central Mediterranean (Ionian and the Adriatic Sea). Other notable regions with nighttime MCS initiation are the sea areas around Corsica and Sardinia Islands as well as the Aegean Sea, where, abrupt land-sea distribution and complex terrain in coastal regions exist.

The mean cloud speed of the examined MCSs during daytime and nighttime (Table 5) is similar (41.8 $\mathrm{km} / \mathrm{h}$ and $43.7 \mathrm{~km} / \mathrm{h}$, respectively) and very close to the mean speed of MCSs according to other studies which used satellite imagery to monitor MCS $[18,19]$. Nevertheless, the small difference between these values is statistically significant, meaning that during nighttime, the MCSs are moving slightly faster than during daytime.

\subsection{Seasonal Characteristics}

The examined sample of the 2344 MCSs which have $\mathrm{CC}_{\text {localmax }}$ events during their lifecycles was also split according to the cold (October to March) and the warm (April to September) period of the year (Table 6 and Figure 4). According to Table 6, in the majority of the basic parameters which characterize the cold and the warm season MCS, it was found that seven out of nine examined parameters have statistically significant different mean values (95\% statistical confidence level or 0.05). More specifically, the MCSs found during the cold season of the year travel a longer distance with greater mean speed $(44.42 \mathrm{~km} / \mathrm{h})$ than those of warm season $(40.65 \mathrm{~km} / \mathrm{h})$. Moreover, the mean MCS cloud speed difference in these two periods was statistically significant, meaning that during the cold season, the MCSs are moving faster than those over the warm period.

Table 6. Basic descriptive statistics for the number of MCSs with at least one $\mathrm{CC}_{\text {localmax }}$ event during the cold and the warm season of the year. The values of the parameter "BT $\operatorname{Diff}(6.2 \mu \mathrm{m}-10.8 \mu \mathrm{m})$ " refer only to the number of MCSs where at least one cloud cell during an MCS lifecycle fulfills this criterion “BT ${ }_{\text {Diff( } 6.2 \mu \mathrm{m}-10.8 \mu \mathrm{m})}>0 \mathrm{~K}$ " (596 MCS out of 2344 in total). The asterisk (“*”) represents statistically significant differences of the mean values (95\% statistical confidence level).

\begin{tabular}{|c|c|c|c|c|c|c|c|}
\hline $\begin{array}{l}\text { MCS Parameters } \\
\text { [Units] }\end{array}$ & $\begin{array}{c}\text { Period } \\
\text { Cold: “0” } \\
\text { Warm: “1” }\end{array}$ & $\mathbf{N}$ & Mean & StDev & $\begin{array}{c}\text { 1st } \\
\text { Quartile } \\
\left(Q_{25 \%}\right)\end{array}$ & $\begin{array}{l}\text { Median } \\
\left(Q_{50 \%}\right)\end{array}$ & $\begin{array}{c}\text { 3rd } \\
\text { Quartile } \\
\left(Q_{75 \%}\right)\end{array}$ \\
\hline \multirow{2}{*}{$\begin{array}{l}\text { Duration } \\
\text { [min] }\end{array}$} & 0 & 1236 & 315.72 & 199.31 & 180.0 & 255.0 & 390.0 \\
\hline & 1 & 1108 & 306.34 & 181.66 & 180.0 & 255.0 & 375.0 \\
\hline \multirow{2}{*}{$\begin{array}{l}\text { *Total Distance } \\
{[\mathrm{km}]}\end{array}$} & 0 & 1236 & 387.29 & 345.40 & 172.47 & 274.31 & 478.36 \\
\hline & 1 & 1108 & 315.50 & 310.58 & 129.24 & 218.52 & 384.73 \\
\hline \multirow{2}{*}{$\begin{array}{c}*(\text { Areal Extent })_{\max } \\
{\left[\mathrm{Km}^{2}\right]}\end{array}$} & 0 & 1236 & $14,138.6$ & $20,734.2$ & 3826.7 & 7327.5 & $16,685.5$ \\
\hline & 1 & 1108 & $13,569.3$ & $29,765.9$ & 3367.5 & 6273.1 & $12,769.8$ \\
\hline \multirow{2}{*}{$\begin{array}{c}* \text { Cloud Speed } \\
{[\mathrm{Km} / \mathrm{h}]}\end{array}$} & 0 & 1236 & 44.42 & 11.05 & 36.74 & 44.87 & 51.85 \\
\hline & 1 & 1108 & 40.65 & 12.15 & 31.0 & 40.09 & 48.96 \\
\hline \multirow{2}{*}{ * Total number of local maxima [unitless] } & 0 & 1236 & 2.45 & 1.78 & 1.0 & 2.0 & 3.0 \\
\hline & 1 & 1108 & 2.08 & 1.54 & 1.0 & 2.0 & 3.0 \\
\hline \multirow{2}{*}{$\begin{array}{c}{ }^{*} \text { Channel } 10.8 \mu \mathrm{m}:\left(\mathrm{BT}_{\text {cold } 10 \%}\right)_{\mathrm{min}} \\
{[\mathrm{K}]}\end{array}$} & 0 & 1236 & -54.87 & 4.06 & -57.38 & -54.45 & -51.84 \\
\hline & 1 & 1108 & -55.48 & 3.74 & -57.98 & -55.37 & -52.74 \\
\hline \multirow{2}{*}{$\begin{array}{c}{ }^{*} \text { Channel } 6.2 \mu \mathrm{m}:\left(\mathrm{BT}_{\text {cold } 10 \%}\right)_{\mathrm{min}} \\
{[\mathrm{K}]}\end{array}$} & 0 & 1236 & -55.14 & 3.55 & -57.36 & -54.77 & -52.66 \\
\hline & 1 & 1108 & -54.69 & 3.28 & -56.84 & -54.48 & -52.34 \\
\hline \multirow{2}{*}{$\begin{array}{c}\mathrm{BT}_{\mathrm{Diff}(6.2 \mu \mathrm{m}-10.8 \mu \mathrm{m})}>0 \mathrm{~K} \\
{[\%]}\end{array}$} & 0 & 314 & 12.9 & 14.2 & 2.1 & 7.7 & 19.9 \\
\hline & 1 & 282 & 17.1 & 18.4 & 2.7 & 9.6 & 27.8 \\
\hline \multirow{2}{*}{$\begin{array}{c}* \mathrm{BT}_{\operatorname{Diff}(6.2 \mu \mathrm{m}-7.3 \mu \mathrm{m})}>-5 \mathrm{~K} \\
{[\%]}\end{array}$} & 0 & 1236 & 97.8 & 2.1 & 96.7 & 98.9 & 100 \\
\hline & 1 & 1108 & 98.2 & 1.8 & 96.4 & 99.4 & 100 \\
\hline
\end{tabular}




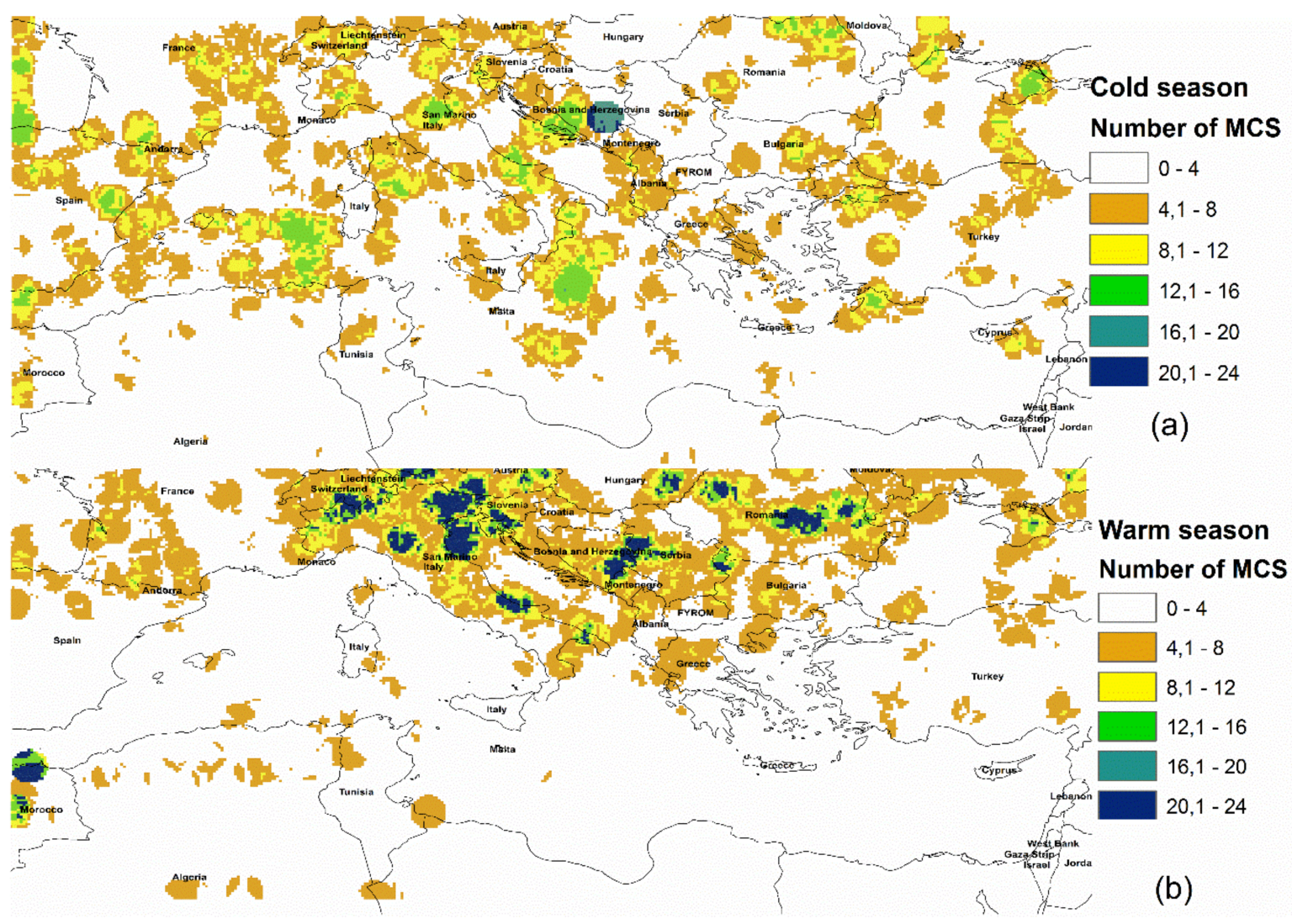

Figure 4. Spatial density of occurrence for the MCSs with at least one $\mathrm{CC}_{\text {localmax }}$ event during (a) cold season; (b) warm season.

Also, it was found that the MCSs of the cold period have more $\mathrm{CC}_{\text {localmax }}$ events on average, in opposition to the MCSs of the warm season. Nevertheless, during the warm season, the mean brightness temperature in the channel of $10.8 \mu \mathrm{m}$, which is the most representative for the MCS detection from satellite images, is lower than the relative value for the MCSs during the cold season of the year. Also, it is noted that the MCSs during the warm season have a higher mean percentage of their cloud tops with temperature differences $\mathrm{BT}_{\text {Diff( } 6.2 \mu \mathrm{m}-10.8 \mu \mathrm{m})}>0 \mathrm{~K}$ and the $\mathrm{BT}_{\text {Diff( }(6.2 \mu \mathrm{m}-7.3 \mu \mathrm{m})}>$ $-5 \mathrm{~K}$ than the relative ones for the MCSs during the cold season.

From Figure 4, it can be seen that the spatial density of occurrence for the MCSs with at least one $\mathrm{CC}_{\text {localmax }}$ event during the cold season is expanding all over the Mediterranean basin, having notable values of concentration above the sea (mainly in the central and western Mediterranean Sea). During the warm season of the year, the MCSs with oscillating behavior are concentrated inland and around the most important mountain ridges (especially around the Alps, the Dinaric Alps, and the Pyrenees) in the northern part of the Mediterranean basin.

\subsection{Land-Sea Distribution}

Dividing the examined sample of the 2344 MCSs which have $\mathrm{CC}_{\text {localmax }}$ events during their lifecycles to land-initiated and sea-initiated, it can be seen that there are small differences, comparing the mean values of their basic parameters (Table 7). Only three out of nine parameters have statistically significant differences in the mean values. This result indicates that the land-sea distribution itself cannot discriminate possible different characteristics of MCSs concerning their dynamics and their oscillating behavior. Nevertheless, regarding the number of MCSs first located above land and sea, this discrimination indicates that the majority of these cloud systems are detected mainly above land. 
Table 7. Basic descriptive statistics for the number of MCSs with at least one $\mathrm{CC}_{\text {localmax }}$ event which first

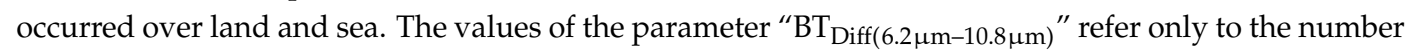
of MCSs where at least one cloud cell during an MCS lifecycle fulfills this criterion "BT Diff $(6.2 \mu \mathrm{m}-10.8 \mu \mathrm{m})$ $>0 \mathrm{~K}^{\prime \prime}$ (596 MCS out of 2344 in total). The asterisk (“*”) represents statistically significant differences of the mean values (95\% statistical confidence level).

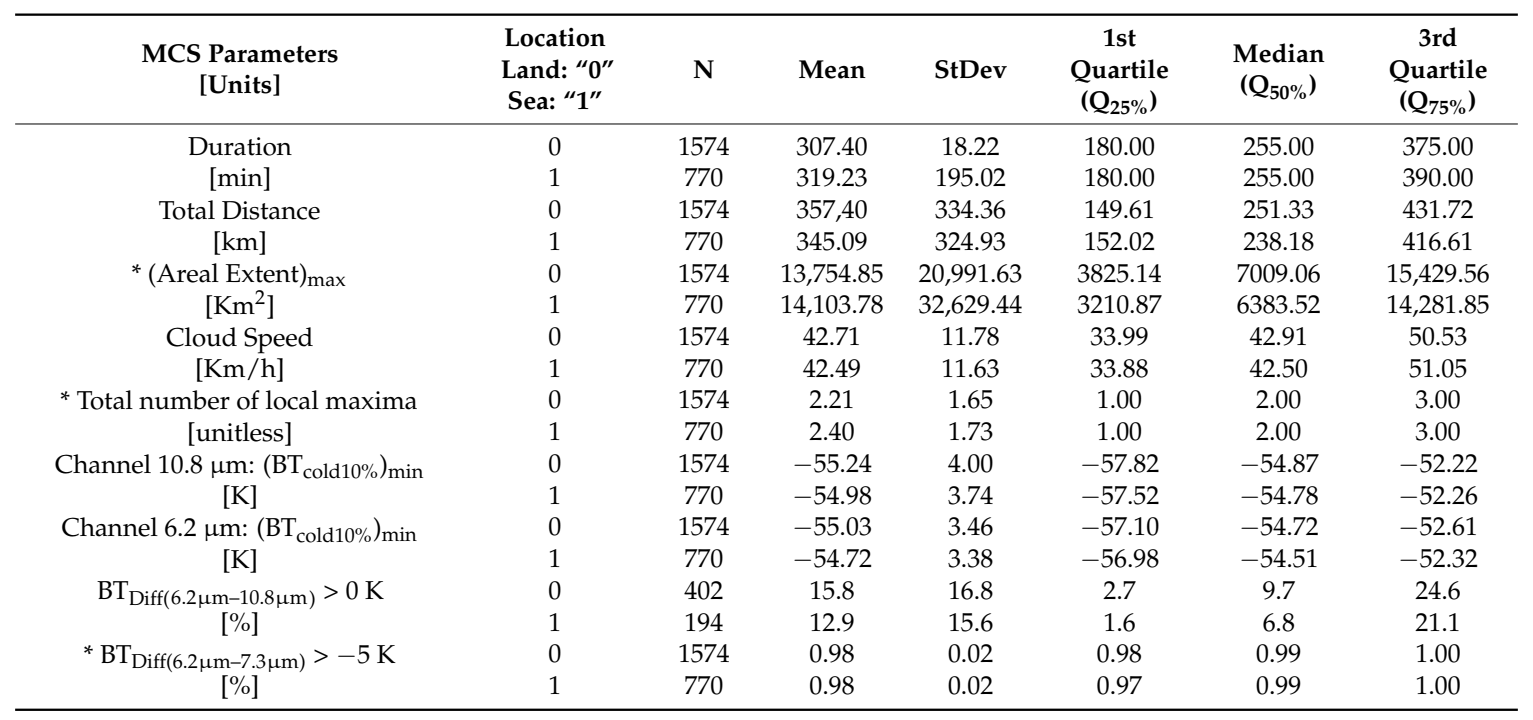

Mapping the spatial density of occurrence for the MCSs with at least one $\mathrm{CC}_{\text {localmax }}$ event that was first located over land and sea (Figure 5), the catalytic role of the topography in triggering MCSs with additional oscillating behavior is observed. The land-initiated MCSs are mainly concentrated around all of the major mountain ridges in the study area (the Atlas Mountains, Pyrenees, Alps, Dinaric Alps, and the Carpathians). Concerning sea-initiated MCSs, their major concentrations are in the central Mediterranean Sea and more specifically in the Adriatic and the Ionian Sea. Important concentration values are also found in the western Mediterranean Sea as well as in the Black Sea. Indeed, it is well known that the topography is a significant factor that triggers MCSs. Considering the fact that in the Mediterranean basin, the MCSs usually have a lifecycle of two to five hours and travel at about 200 to $500 \mathrm{~km}$, e.g., [18,19], their frequency of occurrence around the most important mountainous areas of the study area (Figure 5) can underline topography as a notable cause of the MCS development. In Figure 5, it is also noted that in the eastern Mediterranean, there is a very small number of MCS. Indeed, in this region, there are fewer extended and high mountains compared with other parts of the Mediterranean. Additionally, the sea-atmosphere interactions include complex procedures, especially in triggering convection. More specifically, there are studies which focus on the eastern Mediterranean, where the relatively high values of the SST (in opposition to the western and the northern Mediterranean) are linked with a small number of cases of heavy precipitation (which usually originates from convective clouds) and cloud convection [32,33]. 


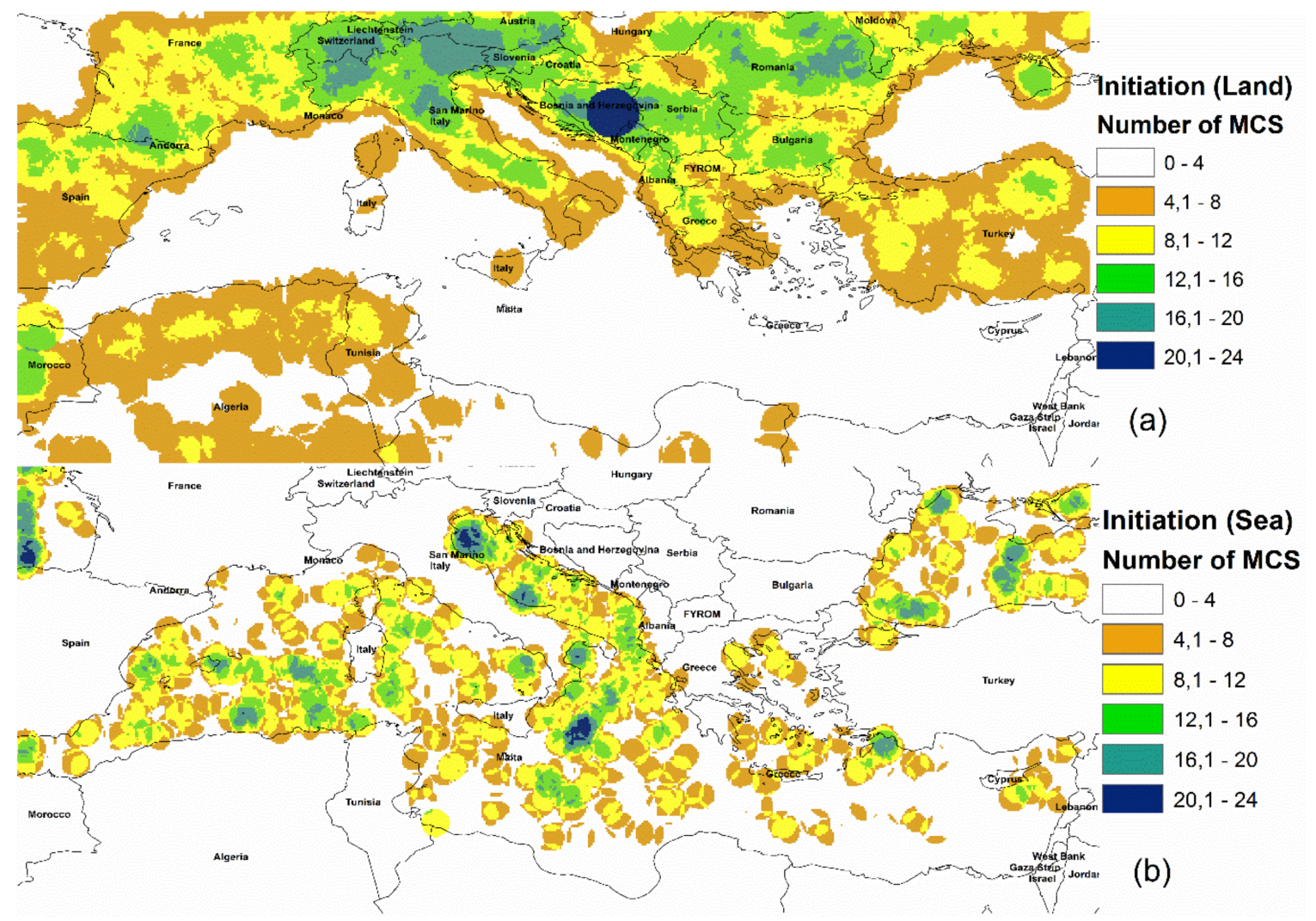

Figure 5. Spatial density of occurrence for the MCSs with at least one $\mathrm{CC}_{\mathrm{CClocalmax}}$ event that first occurred (a) on land; (b) sea.

\section{Discussion}

One main result of this study is the significant role of the orography and the heating of the ground during the daytime in the development of MCSs capable of producing CGWs. Indeed, it is well known that cloud convection, which is often triggered when the solar heating of the lower part of the troposphere cause instability, expands the height of the planetary boundary layer and forms a lapse rate which allows the warm and humid air masses at the surface to rise vertically. The vertical movement of air masses and the creation of updrafts (core components of cloud storm initiation) as well as its intensification, can be triggered (or enhanced) by the orography which operates as a lifting mechanism of warm and humid air masses, capable of evolving to well-organized convective cloud systems. Such conditions can exist during daytime and especially during the warm season of the year, explaining the distribution of MCSs in these cases (Figures 3 and 4). The thermal heating mainly during the warm season and in the daytime (in combination with topography) can create strong updrafts which help the convective cloud top to reach high in the troposphere (very cold cloud tops) and become optically thick, almost in their whole structure. Nevertheless, these updrafts seem to not exclusively affect the oscillating behavior of these cloud systems. More specifically, during the warm season and daytime, the numbers of CQWs cases are the lowest (Figure 2a,b).

During nighttime, the temperature profile of the earth's surface is very different from that during daytime. In the absence of synoptic features, the local characteristics seem to prevail in the initiation of MCSs with $\mathrm{CC}_{\text {localmax }}$ events during their lifecycles. More specifically, a significant number of nocturnal MCSs are located near coasts as well as in narrow but deep-sea areas, surrounded by land with complex topography (Adriatic and the Ionian Sea). The concentration of the majority of the nocturnal MCS around such areas (Figure 3) is due to local air flows from the cold land to the relatively warm sea surface. More specifically, considering the absence of synoptic scale affections, 
during nighttime and additionally in the cold period of the year, the land is usually colder than the sea surface. Under such conditions, cool air from inland can move and rise above the warmer sea. In elongated sea bands (e.g., Adriatic Sea), surrounded by a complex terrain, this phenomenon can occur on both of the sea sides, practically creating an extended convergence zone in the sea area where these ("land-breeze" like) air flows meet. The convergence zone can promote the upward movement of relatively warm and humid air masses, finally producing cloud storms. This explanation can be an additional factor in the low-pressure systems which are an important source of MCS production. Another factor which may notably contribute to MCSs with oscillating behavior is the air temperature inversion in combination with the upwelling [34]. The air temperature inversion can occur when a warmer, less dense air mass moves over a cooler, denser air mass. This type of inversion occurs in the vicinity of warm fronts, and also in sea areas where upwelling can occur. Furthermore, the coastal upwelling can be intensified by alongshore winds, which strengthen in proportion to the temperature differences of the land-sea air masses [34]. Although the inversion prevents the vertical movement of an air mass, cloud convection may be present (even at the embryonic stage) in the cooler air masses at the surface. If the inversion is extended above sea areas, the air masses below the layer of the inversion can gradually increase their humidity by evaporation at the sea surface, as well as by the effect of cooling itself. At this point, the colder layer may be relatively warm but denser and usually cooler than the lower part of the inversion layer. When the inversion layer is shifted gradually over warmer waters (usually coastal areas with relatively shallow water depth), the possible turbulence within the cooler layer below the base of the inversion can gradually lift the inversion layer to higher altitudes, and eventually even pierce it, finally producing cloud storms. All the factors mentioned above can be linked with the development of MCSs during nighttime, in the cold season of the year and above the sea. Although such conditions as these described before are not always capable of generating strong updrafts during MCS development, according to the results of Figure 2a,b, such conditions can favor the development of a notable number of MCS with $\mathrm{CC}_{\mathrm{CClocalmax}}$ events, leading to CGW production.

\section{Conclusions}

In this study, the basic characteristics of the MCSs which can be considered capable of producing CGWs were determined. An algorithm that uses as input data the multispectral satellite imagery of the SEVIRI instrument (on-board of Meteosat-10 satellite platform) was used to record MCS lifecycles. The areal changes of the MCS cloud tops during their entire lifecycle can characterize their pulsating behavior (MCs oscillations), and the most significant maxima during these areal changes $\left(\mathrm{CC}_{\text {localmax }}\right.$ events) are considered capable of producing gravity waves of convective nature (convective gravity waves, "CGWs").

During the analysis, firstly, all the cloud tops that represent $\mathrm{CC}_{\text {localmax }}$ events were selected, and basic statistics for these cloud patterns were calculated to give a mean profile regarding these events that are considered capable of producing CQWs. From Table 2, it is concluded that these cloud tops are very cold $\left(-53^{\circ} \mathrm{C}\right)$ and are thus located high in the troposphere. Also, they extend over thousands of square kilometers (mean areal size of $1455 \mathrm{~km}^{2}$ ), which corresponds to well-organized convection. Moreover, they have high cooling rates $\left(3{ }^{\circ} \mathrm{C} / \mathrm{min}\right)$ that represent active and intense updrafts. The mean number of $\mathrm{CC}_{\text {localmax }}$ events per hour (frequency of oscillations) was 0.46 or one event every $133 \mathrm{~min}$. The mean distance between two consecutive $\mathrm{CC}_{\text {localmax }}$ events (wavelength of oscillations) is $139.08 \mathrm{~km}$ while the mean horizontal speed was $18.9 \mathrm{~m} / \mathrm{s}$, i.e., statistics that are similar to other related studies [17].

In an effort to detect possible causes as well as favorable periods of time and regions for the development of MCSs capable of producing CQWs, the studied sample of MCSs was categorized between daytime-nighttime, warm-cold period of the year and land-sea cases. For each of these subcategories, main statistics for a set of basic MCS parameters that can be calculated from satellite images was calculated, and the statistical significance of their parameter differences between the abovementioned subcategories was also extracted (Tables 5-7). 
The analysis revealed that all of the detected MCSs during nighttime, in the cold season and those that were sea-initiated, are longer lasting, have a greater areal extent, but reach lower in the atmosphere (according to their mean cloud temperature values) compared with the MCSs during the daytime, in the warm season and those that are land-initiated, respectively. Also, they have smaller percentages of their cloud top areas which are characterized as optically thick. Nevertheless, they have a higher mean number of $\mathrm{CC}_{\text {localmax }}$ events during their lifecycles which indicate that they can be more productive in CQW generation.

Another important finding is that the MCSs with oscillating behavior do not differ between land-initiated and sea-initiated regarding the mean values their basic parameters. Nevertheless, the number of land-initiated MCSs comprise $67.2 \%$ of the total number of the examined MCS and they present a high density of occurrence around all of the significant mountain ridges in the study area. Concerning the sea-initiated MCSs, they are significantly lower in number (32.8\% of the total) and are concentrated mainly in the central and the western Mediterranean Sea. These geographic areas, either inland or in the sea, seem to concentrate a notable MCS number capable of producing CGW.

It is important to note that the criteria used to detect and monitor the MCSs in the satellite images can notably affect their characteristics (e.g., their life cycle duration, their areal extent, etc.). Nevertheless, the criteria chosen are widely used worldwide and have been already proven effective in the detection and monitoring convection in the studies where they were proposed and performed [25]. Additionally, the algorithm used in this study is well tested and has been already used in previous studies on cloud convection and thresholding criteria [19,22-24].

The findings of this study can serve as an indicator for further analysis and future work regarding the internal structure of the convective clouds which are capable of producing CGWs. Additionally, this study can serve as a precursor to examine the analytical characteristics of the preferred regions for the development of MCSs capable of producing CGWs and how these MCSs can affect the vertical structure of the troposphere and the energy/momentum exchange between the tropopause and the lower stratosphere.

Acknowledgments: The author would like to express their appreciation to the anonymous reviewers for their constructive comments that helped to improve the completeness and clarity of the paper. He would also like to thank the European Organization for the Exploitation of the Meteorological Satellites (EUMETSAT) and all its agencies for the freely available Meteosat datasets.

Author Contributions: Stavros Kolios is the exclusive author of this research study. He conceived, designed and performed all the experiments, analyzed the data, presented the results and conclusions and wrote the paper.

Conflicts of Interest: The author declares no conflicts of interest.

\section{References}

1. Fovell, R.; Durran, D.; Holton, J.R. Numerical simulations of convectively generated stratospheric gravity waves. J. Atmos. Sci. 1992, 49, 1427-1442. [CrossRef]

2. Alexander, M.J.; Barnett, C. Using satellite observations to constrain gravity wave parametrizations for global models. J. Atmos. Sci. 2007, 64, 1652-1665. [CrossRef]

3. Fritts, D.C.; Alexander, M.J. Gravity wave dynamics and effects in the middle atmosphere. Rev. Geophys. 2003, 41, 1003. [CrossRef]

4. Song, I.S.; Chun, H.Y.; Lane, T.P. Generation mechanisms of convectively forced internal gravity waves and their propagation to the stratosphere. J. Atmos. Sci. 2003, 60, 1960-1980. [CrossRef]

5. Lane, T.P.; Sharman, R.D. Gravity wave breaking, secondary wave generation, and mixing above deep convection in a three-dimensional cloud model. Geophys. Res. Lett. 2006, 33, L23813. [CrossRef]

6. Wei, J.; Zhang, F. Mesoscale Gravity Waves in Moist Baroclinic Jet-Front Systems. J. Atmos. Sci. 2013, 71, 929-952. [CrossRef]

7. Zhang, X.; Pang, J. A comparison between atmospheric water vapor content retrieval methods using MSG2-SEVIRI thermal-IR data. Int. J. Remote Sens. 2015, 36, 5075-5086. [CrossRef]

8. Lane, T.P.; Reeder, M.J. Convectively generated gravity waves and their effect on the cloud environment. J. Atmos. Sci. 2001, 58, 2427-2440. [CrossRef] 
9. Pasko, V.P.; Inan, U.S.; Bell, T.F. Sprites as evidence of vertical gravity wave structures above mesoscale thunderstorms. Geophys. Res. Lett. 1997, 24, 1735-1738. [CrossRef]

10. Sentman, D.D.; Wescott, E.M.; Picard, R.H.; Winick, J.R.; Stenbaek-Nielsen, H.C.; Dewan, E.M.; Moudry, D.R.; Sao Sabbas, F.T.; Heavner, M.J.; Morrill, J. Simultaneous observations of mesospheric gravity waves and sprites generated by a midwestern thunderstorm. J. Atmos. Sol. Terr. Phys. 2003, 65, 537-550. [CrossRef]

11. Pautet, P.D.; Taylor, M.J.; Liu, A.Z.; Swenson, G.R. Climatology of short-period gravity waves observed over northern Australia during the Darwin Area Wave Experiment (DAWEX) and their dominant source regions. J. Geophys. Res. 2005, 110, D03S90. [CrossRef]

12. Yue, J.; Vadas, S.L.; She, C.Y.; Nakamura, T.; Reising, S.C.; Liu, H.L.; Stamus, P.; Krueger, D.A.; Lyons, W.; Li, T. Concentric gravity waves in the mesosphere generated by deep convective plumes in the lower atmosphere near Fort Collins, Colorado. J. Geophys. Res. 2009, 114, D06104. [CrossRef]

13. Kalisch, S.; Chun, H.-Y.; Ern, M.; Preusse, P.; Trihn, G.T.; Eckermann, S.D.; Riese, M. Comparison of simulated and observed convective gravity waves. J. Geophys. Res. Atmos. 2016, 121, 13474-13492. [CrossRef]

14. Rechou, A.; Arnault, J.; Dalin, P.; Kirkwood, S. Case study of stratospheric gravity waves of convective origin over Arctic Scandinavia-VHF radar observations and numerical modelling. Annal. Geophys. 2013, 31, 239-250. [CrossRef]

15. Dörnbrack, A.; Gisinger, S.; Kaifler, B. On the Interpretation of Gravity Wave Measurements by Ground-Based Lidars. Atmosphere 2016, 8, 49. [CrossRef]

16. Jewtoukoff, V.; Plougonven, R.; Hertzog, A. Gravity waves generated by deep tropical convection: Estimates from balloon observations and mesoscale simulations. J. Geophys. Res. Atmos. 2013, 118, 9690-9707. [CrossRef]

17. Blanc, E.; Farges, T.; Le Pichon, A.; Heinrich, P. Ten-year observations of gravity waves from thunderstorms in western Africa. J. Geophys. Res. Atmos. 2014, 119, 6409-6418. [CrossRef]

18. Morel, C.; Senesi, S.A. climatology of mesoscale convective systems over Europe using satellite infrared imagery. II. Characteristics of European mesoscale convective systems. Q. J. R. Meteorol. Soc. 2002, 128, 1973-1995. [CrossRef]

19. Kolios, S.; Feidas, H. A warm season climatology of Mesoscale Convective Systems in the Mediterranean basin using satellite data. Theor. Appl. Clim. 2010, 102, 29-42. [CrossRef]

20. Levizzani, V.; Pinelli, F.; Pasqui, M.; Melani, S.; Laing, A.G.; Carbone, R.E. A 10-year climatology of warm-season cloud patterns over Europe and the Mediterranean from Meteosat IR observations. Atmos. Res. 2010, 97, 555-576. [CrossRef]

21. Kotroni, V.; Lagouvardos, K. Lightning in the Mediterranean and its relation with sea-surface temperature. Environ. Res. Lett. 2015, 11, 034006. [CrossRef]

22. Kolios, S. Development of Automated System for the Very Short-Range Forecast of Mesoscale Convective Systems Using Meteosat Satellite Imagery. Ph.D. Dissertation, Aegean University, Mytilene, Greece, 2009.

23. Kolios, S.; Feidas, H. An automated nowcasting system of Mesoscale Convective Systems for the Mediterranean basin using Meteosat imagery. Part I: System description. Meteorol. Appl. 2012, 20, 287-295. [CrossRef]

24. Kolios, S.; Feidas, H. An automated nowcasting system of Mesoscale Convective Systems for the Mediterranean basin using Meteosat imagery. Part II: Verification statistics. Meteorol. Appl. 2012, 20, 296-307. [CrossRef]

25. Merk, D.; Zinner, T. Detection of convective initiation using Meteosat SEVIRI. Atmos. Meas. Tech. 2013, 6, 1903-1918. [CrossRef]

26. Kolios, S.; Stylios, C. Combined use of an instability index and SEVIRI water vapor imagery to detect unstable air masses. In Proceedings of the EUMETSAT Meteorological Satellite Conference, Geneva, Switzerland, 22-26 September 2014.

27. Schmetz, J.; Tjmekes, S.A.; Gube, M.; Van de Berg, L. Monitoring deep convection and convective overshooting with METEOSAT. Adv. Space Res. 1997, 19, 433-441. [CrossRef]

28. Lattanzio, A.; Watts, P.D.; Govaerts, Y. Activity Report on Physical Interpretation of Warm Water Vapour Pixels; Programme Development Department, Technical Memorandum, EUMETSAT: Darmstadt, Germany, 2005.

29. Wilks, D. Statistical Methods in the Atmospheric Sciences, 3rd ed.; Academic Press: Cambridge, MA, USA, 2011; ISBN 9780123850232. 
30. Mazon, J.; Pino, D. Role of the nocturnal coastal-front depth on cloud formation and precipitation in the Mediterranean basin. Atmos. Res. 2015, 153, 145-154. [CrossRef]

31. Mazon, J.; Pino, D. The Influence of an Increase of the Mediterranean Sea Surface Temperature on Two Nocturnal Offshore Rainbands: A Numerical Experiment. Atmosphere 2017, 8, 58. [CrossRef]

32. Shaltout, M.; Omstedt, A. Recent sea surface temperature trends and future scenarios for the Mediterranean Sea. Oceanologia 2014, 56, 411-443. [CrossRef]

33. Kolios, S.; Stylios, C. Spatiotemporal relation between sea surface temperature and cloud convection in the Mediterranean basin during warm season. Earth observation for ocean-atmosphere interactions science. In Proceedings of the European Space Agency Workshop, Rome, Italy, 28-31 October 2014.

34. Sydeman, W.J.; García-Reyes, M.; Schoeman, D.S.; Rykaczewski, R.R.; Thompson, S.A.; Black, B.A.; Bograd, S.J. Climate change and wind intensification in coastal upwelling ecosystems. Science 2014, 345, 77-80. [CrossRef] [PubMed]

(C) 2018 by the author. Licensee MDPI, Basel, Switzerland. This article is an open access article distributed under the terms and conditions of the Creative Commons Attribution (CC BY) license (http://creativecommons.org/licenses/by/4.0/). 